Rana M. Fadhil BDS (P.G. Student)

Ali R. Al-Khatib BDS, MSc, PhD (Asst. Prof.)

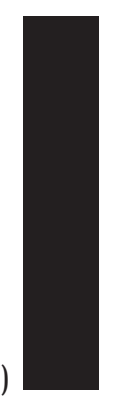

\section{Assessment of Cortical Bone Density
for Orthodontic Implants Placement: \\ Assessment of Cortical Bone Density
for Orthodontic Implants Placement: Computerized tomography study}

\author{
Nineveh Health Directorate \\ Ministry of Health
}

Dept of Pedod, orthod and Prev Dentistry College of Dentistry, University of Mosul

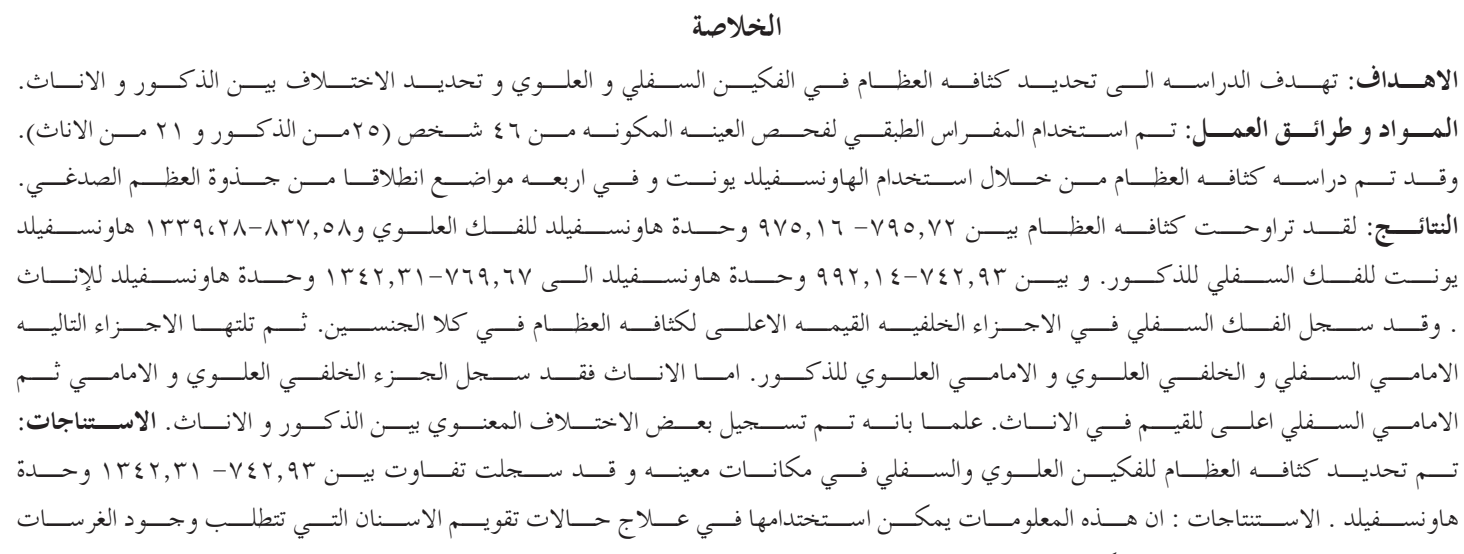

\title{
ABSTRACT
}

Aims: The aims of this study were to investigate the bone density in the buccal surface of the maxilla and mandible and to assess the gender difference. Materials and Methods: The study was conducted using computed tomography images for the 46 subjects ( 25 males and 21 females). Based on computed tomography data, the mean bone density values in Hounsfield units were recorded at 4 different locations from the crest of alveolar bone. Results: The bone density ranged from 795.72- 975.16 Hounsfield units in the maxilla and 837.58- 1339.28 Hounsfield units in the mandible for male and from 742.93-992.14 and 769.67- 1342.31 Hounsfield units in the maxilla and mandible for female respectively. It was found that the mandibular posterior bone had the highest cortical bone in both sexes, followed by, mandibular anterior, maxillary posterior and maxillary anterior areas in male. In female, the sequence of bone density from highest to lowest was maxillary posterior bone, maxillary anterior and mandibular anterior areas. There was significant difference between males and females in some locations with higher bone densities in males $(\mathrm{p}<0.05)$. Conclusions: Bone densities in the buccal maxillary and mandibular areas were presented. They were ranged between 742.93-1342.31 Hounsfield units in various areas. These data can be used in dental implant treatment planning to avoid associated risk factors.

Key words: Bone density, Computed tomography, Implant.

Fadhil RM, Al-Khatib AR, Assessment of Cortical Bone Density for Orthodontic Implants Placement: Computerized tomography study. Al-Rafidain Dent J. 2015; 15(1): 393-398.

Received: $25 / 6 / 2013$

Sent to Referees: $26 / 6 / 2013$

Accepted for Publication: 18/8/2013

\section{INTRODUCTION}

Orthodontic implant gains a wide acceptance as an anchorage means in orthodontic treatment. ${ }^{(1)}$ Its successful outcome depends on a series of patient and procedure related factors and one of these is the cortical bone thickness and density ${ }^{(2,3,4)}$. Density of the cortical bone may be considered as useful factor because it contributes to the stability of orthodontic implants. ${ }^{(4,5)}$ For that reason, proper assessment of bone density is important in any treatment plan involving implants.

Several attempts have been made to assess bone density utilizing different tools ${ }^{(6,7)}$. They are conducted either on bone sections, cadaver and edentulous areas. Other studies were conducted on specific sites of maxilla and mandible for the dental rather than orthodontics implant (7),9,10). $^{2}$.

In the literature, Choi et al. ${ }^{(11)}$ determine cortical bone density at various depths of orthodontic implant insertion sites. They recorded that mean bone density in the maxilla was lowest at the maxillary tuberosity and the density had a tendency to increase progressively from the posterior to the anterior 
areas. The highest bone density was recorded between the central and lateral incisors. In the mandible, the buccal side between the first and second molars had the highest value.

To date, studies on bone density of orthodontic implants are comparatively few ${ }^{(11,12,13,14)}$. And according to the best knowledge of authors, there is no study has been conducted on Iraqi regarding this topic. Thus, the aims of the present study were to evaluate the cortical bone density in various buccal maxillary and mandibular sites and determine the related sexual dimorphism.

\section{MATERIALS AND METHODS}

The approval was obtained from the Ethical Committee in its session No. 9 in 28/6/2012 and the Scientific Committee for Researches, in its session No. 142 in 10/7/2012 at Directorate of Health Nineveh.

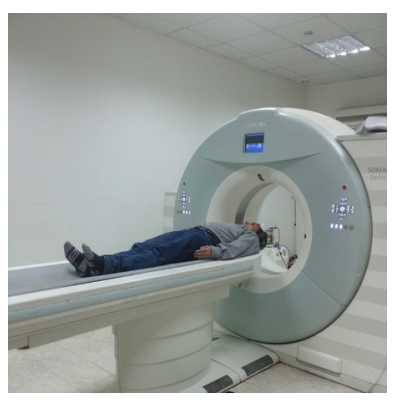

Figure (1): The pictures show the position of the subject on scan table.

The scanning conditions were standardized at $120 \mathrm{kV}, 47 \mathrm{~mA}$ with scanning time of 7.32 seconds and effective radiation dose of $0.21 \mathrm{mSv}$. Syngo ct 2011a, Siemens, Germany software, was used to measure bone density in Hounsfield units (HU) and to construct images with a mode of $0.8 \mathrm{~mm}$ slice thickness, $0.6 \mathrm{~mm}$ distance between slices. The cortical bone density was measured at 4 locations which were: $2,4,6$, and $8 \mathrm{~mm}$ height from the alveolar bone crest. The measurements were conducted at the inter-dental area between the two central incisors moving distally to the second molar
The sample consisted of multi-slice computerized tomography (CT) scans (CTAWP64958, Siemens, Germany) of 46 volunteers at Ibn- Sina Teaching Hospital in Mosul City. The study groups included 25 males and 21 Females with age range 18-35 years. Exclusion criteria included any subject with history of systemic disease, clinically obvious periodontal problem, apparent facial asymmetry, absence of any permanent teeth except for the third molars, impacted teeth except for the third molar and poor quality $\mathrm{CT}$ volumetric data with indistinct cortical borders or artifacts.

The subject was scanned in the supine position, from the chin upward. The subject's head was adjusted so that the Frankfort horizontal plane was perpendicular to the floor of the scanner as shown in Figure (1).

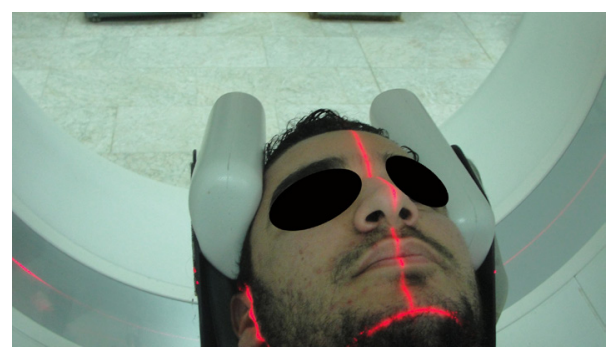

in both sides.

To measure the cortical bone density at each area, two points between the adjacent teeth in the buccal and palatal or lingual cortical sites were selected. These points were determined by perpendicular sectioning of a line drown from prominent proximal pulp of one tooth to the most prominent proximal pulp of the adjacent one. The peripheral buccal cortical end of the perpendicular line was selected to represent the site of bone density measurement (Figure (2)). To test the intra-examiner reliability, the variables of 5 subjects were measured twice

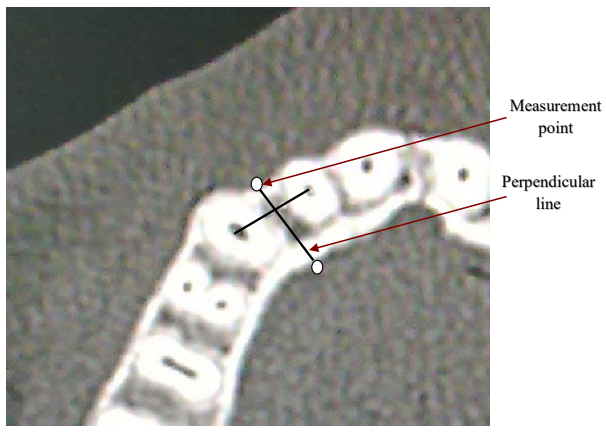

Figure (2): Diagrammatic Illustration shows the lines and points used for measuring the bone density. 
in 2 weeks interval by same examiner. The method error was calculated by paired ttest with no significant difference in trend according to area.

Statistical analysis was carried out by using SPSS software (version 18.0, SPSS, Chicago, I11). First, descriptive statistics were used to summarize the sample and then paired t- test was used to compare mean bone densities between the contra-lateral sides. The means and standard deviations of bone density were computed for each site in the maxilla and mandible for males and females. Student t- test was used to compare difference between sexes in each arch.

\section{RESULTS}

Forty- six subjects were participated in this study. It has been found that the bone density in all subjects ranged 795.72-975.16 $\mathrm{HU}$ in the maxilla and 837.58- $1339.28 \mathrm{HU}$ in the mandible for male and from 742.93992.14 and 769.67- 1342.31 HU in the maxilla and mandible for female respectively (Tables (1) and (2))

Table (1) :Comparison of gender difference in cortical bone density of the maxilla.

\begin{tabular}{|c|c|c|c|c|c|c|c|}
\hline \multirow{2}{*}{$\begin{array}{l}\text { Measurement } \\
\text { Location }\end{array}$} & \multirow{2}{*}{ Site } & \multicolumn{2}{|c|}{ Males } & \multicolumn{2}{|c|}{ Females } & \multirow{2}{*}{ t-value } & \multirow{2}{*}{$p$-value } \\
\hline & & Mean & SD & Mean & SD & & \\
\hline \multirow{7}{*}{ Location 1} & $1-1$ & 795.72 & 148.98 & 865.38 & 129.32 & -1.68 & 0.101 \\
\hline & $1-2$ & 898.60 & 169.10 & 803.29 & 97.62 & 2.82 & $0.027^{*}$ \\
\hline & $2-3$ & 835.06 & 123.37 & 742.93 & 145.18 & 2.33 & $0.025^{*}$ \\
\hline & $3-4$ & 845.08 & 131.41 & 793.00 & 127.95 & 1.36 & 0.182 \\
\hline & $4-5$ & 908.74 & 140.79 & 888.62 & 144.53 & 0.48 & 0.636 \\
\hline & $5-6$ & 817.32 & 101.15 & 830.05 & 106.18 & -0.42 & 0.680 \\
\hline & $6-7$ & 849.16 & 122.92 & 874.38 & 151.47 & -0.62 & 0.536 \\
\hline \multirow{7}{*}{ Location 2} & $1-1$ & 902.12 & 164.70 & 813.90 & 196.72 & 1.66 & 0.105 \\
\hline & $1-2$ & 912.44 & 132.14 & 866.90 & 136.24 & 1.15 & 0.257 \\
\hline & $2-3$ & 879.90 & 135.49 & 788.19 & 139.30 & 2.26 & $0.029 *$ \\
\hline & $3-4$ & 878.20 & 145.61 & 843.86 & 149.40 & 0.79 & 0.435 \\
\hline & $4-5$ & 845.24 & 132.12 & 890.38 & 134.12 & -1.15 & 0.258 \\
\hline & $5-6$ & 867.42 & 117.57 & 926.07 & 180.34 & -1.33 & 0.192 \\
\hline & $6-7$ & 837.52 & 125.96 & 894.81 & 127.78 & -1.53 & 0.134 \\
\hline \multirow{7}{*}{ Location 3} & $1-1$ & 871.08 & 159.00 & 876.33 & 165.85 & -0.11 & 0.913 \\
\hline & $1-2$ & 947.60 & 138.10 & 918.29 & 129.37 & 0.74 & 0.464 \\
\hline & $2-3$ & 886.70 & 139.14 & 852.74 & 156.13 & 0.78 & 0.440 \\
\hline & $3-4$ & 912.02 & 150.55 & 915.67 & 150.97 & -0.08 & 0.935 \\
\hline & $4-5$ & 914.42 & 155.27 & 965.88 & 161.68 & -1.10 & 0.278 \\
\hline & $5-6$ & 937.64 & 156.07 & 883.90 & 246.12 & 0.90 & 0.374 \\
\hline & $6-7$ & 922.66 & 140.83 & 924.50 & 185.32 & -0.04 & 0.970 \\
\hline \multirow{7}{*}{ Location 4} & $1-1$ & 896.76 & 195.36 & 860.14 & 159.92 & 0.69 & 0.496 \\
\hline & $1-2$ & 974.62 & 139.27 & 939.33 & 157.61 & 0.81 & 0.425 \\
\hline & $2-3$ & 928.40 & 136.13 & 823.12 & 167.25 & 2.35 & $0.023^{*}$ \\
\hline & $3-4$ & 972.52 & 177.60 & 939.45 & 171.81 & 0.64 & 0.527 \\
\hline & $4-5$ & 951.44 & 183.56 & 992.14 & 185.51 & -0.75 & 0.460 \\
\hline & $5-6$ & 957.74 & 182.35 & 866.74 & 286.55 & 1.305 & 0.199 \\
\hline & $6-7$ & 975.16 & 180.91 & 953.31 & 177.06 & -0.15 & 0.879 \\
\hline
\end{tabular}

* Significant difference at $\mathrm{p}<0.05$. 
Fadhil RM, Al-Khatib AR

Table (2) :Comparison of gender difference in cortical bone density of the mandible.

\begin{tabular}{cccccccc}
\hline $\begin{array}{c}\text { Measurement } \\
\text { Location }\end{array}$ & Site & \multicolumn{2}{c}{ Males } & \multicolumn{2}{c}{ Females } & \multirow{2}{*}{ t-value } & p- value \\
\hline & $1-1$ & 873.32 & 142.87 & 769.67 & 170.68 & 2.243 & $0.030^{*}$ \\
& $1-2$ & 864.56 & 115.27 & 781.67 & 140.34 & 2.20 & $0.033^{*}$ \\
& $2-3$ & 831.58 & 125.97 & 807.26 & 114.90 & 0.68 & 0.501 \\
Location 1 & $3-4$ & 935.26 & 117.93 & 851.29 & 155.76 & 2.08 & $0.043^{*}$ \\
& $4-5$ & 985.00 & 116.15 & 952.90 & 166.34 & 0.77 & 0.447 \\
& $5-6$ & 929.42 & 97.14 & 1020.86 & 160.89 & -2.38 & $0.022^{*}$ \\
& $6-7$ & 1077.24 & 154.68 & 1113.00 & 219.33 & -0.65 & 0.521 \\
& $1-1$ & 879.44 & 117.93 & 778.19 & 165.22 & 2.42 & $0.020^{*}$ \\
& $1-2$ & 863.14 & 126.89 & 774.17 & 145.54 & 2.22 & $0.032^{*}$ \\
& $2-3$ & 887.82 & 124.43 & 856.67 & 175.46 & 0.70 & 0.486 \\
Location 2 & $3-4$ & 972.34 & 136.22 & 867.40 & 198.35 & 2.12 & $0.040^{*}$ \\
& $4-5$ & 1055.02 & 150.20 & 998.48 & 205.07 & 1.08 & 0.287 \\
& $5-6$ & 1048.56 & 136.31 & 1039.43 & 176.46 & 0.20 & 0.844 \\
& $6-7$ & 1137.10 & 153.05 & 1172.86 & 207.31 & -0.67 & 0.505 \\
& $1-1$ & 888.88 & 178.97 & 785.24 & 146.24 & 2.123 & $0.039^{*}$ \\
& $1-2$ & 962.28 & 108.11 & 889.81 & 131.04 & 2.06 & $0.046^{*}$ \\
& $2-3$ & 915.34 & 179.40 & 915.71 & 140.53 & -0.01 & 0.994 \\
Location 3 & $3-4$ & 1029.38 & 148.90 & 989.24 & 235.60 & 0.70 & 0.486 \\
& $4-5$ & 1162.22 & 130.94 & 1011.79 & 164.59 & 3.45 & $0.001^{*}$ \\
& $5-6$ & 1151.16 & 148.29 & 1082.45 & 174.56 & 1.44 & 0.156 \\
& $6-7$ & 1278.92 & 162.54 & 1232.88 & 175.01 & 0.92 & 0.361 \\
& $1-1$ & 899.36 & 178.81 & 792.19 & 168.51 & 2.08 & $0.044^{*}$ \\
& $1-2$ & 961.74 & 158.32 & 867.33 & 120.59 & 2.24 & $0.030^{*}$ \\
& $2-3$ & 959.82 & 172.94 & 940.33 & 170.02 & 0.38 & 0.703 \\
& $3-4$ & 1070.10 & 166.41 & 952.05 & 209.98 & 2.13 & $0.039^{*}$ \\
& $4-5$ & 1196.40 & 151.71 & 1088.50 & 201.74 & 2.07 & $0.044^{*}$ \\
& $5-6$ & 1195.72 & 141.16 & 1131.21 & 177.98 & 1.37 & 0.177 \\
& $6-7$ & 1339.28 & 116.34 & 1342.31 & 194.47 & -0.07 & 0.948 \\
\hline Sigation 4
\end{tabular}

* Significant difference at $\mathrm{p}<0.05$.

The bilateral comparisons have shown no significant differences in males except the 4-5 site which was significantly different in all of the study locations at $\mathrm{p}<0.05$. Also, site between $4-5$ at location $2,1-2$ site at location 3 and 2-3 site at locations 3 and 4 in the maxillary buccal side have shown significant differences. Whereas, in the mandible, $4-5$ site was significantly different in all study locations. Moreover, 2-3, 5-6 sites in the locations 1 and 4 were significantly different. In female's maxillary arch, the 1-2 site showed significant difference in all of the locations. Whereas, the $2-3,6-7$ sites in locations 3, 4 and 6-7 site in location 1, 3-4 in location 4 also showed significant differences. However, only, 2-3, 5-6 sites at location 1and 6-7 site at location 2 have shown significant differences at $\mathrm{p}<0.05$.

When the means of the measurement sites were compared in each gender, canine region displayed higher alveolar bone density than incisors in male's maxilla and mamdible. In the maxillary buccal region of the males, cortical bone density was the highest at the 8-mm location (site 6-7) and lowest at the 4-mm location (site 5-6). The mandibular posterior bone density increased progressively with increasing distance from the alveolar crest and was thickest at the 8-mm location. Regarding the bone density values in females, similar trend was observed (Tables (1) and (2))

For the further statistical ysis, the right and left data were pooled (Tables (1) and (2)). Female patients had lower bone densities than male except at posterior maxillary sites at locations 1 and 2 and mandibular posterior sites at location 1 . The statistical significant difference in the mean 
bone density has clearly been recorded at the maxillary and a mandibular labial area as male was significantly higher $(\mathrm{p}<0.05)$.

\section{DISCUSSION}

Methods for measuring the bone density include dual-energy x-ray absorptiometry, CT images, and measuring the blackness in the film or the panoramic mandibular index from conventional radiographic images. ${ }^{(15)}$ Three-dimensional CT bone density can be described in HU. Hounsfield units are standardized according to the attenuation coefficient as follows: water, $0 \mathrm{HU}$; air, $-1000 \mathrm{HU}$; and enamel, $13000 \mathrm{HU} .^{(12)}$

Several authors have studied bone densities for the placement of dental implants and reported overall bone density values different from the present findings ${ }^{(16,17)}$. The reason behind that is the subjects in the earlier studies were older patients with edentulous areas. Moreover, combined densities of cortical and cancellous bone in edentulous ridge areas with thin cortices may result in different values.

Regarding orthodontic implants, bone density was measured in different locations, and depths. ${ }^{(11,12,13,14)}$ The present study measured the density at nearby positions of previous research. ${ }^{(13)}$

Contra- lateral comparisons have shown significant difference in some of the study locations. The possible explanation is related to the subject musculature, if the chewing cycle has a large transverse component it would be expected that medial pterygoid and masseter muscles would be more active on one side, therefore, leading to an increased deposition of cortical bone ${ }^{(18)}$.

In this study, it was found that the mandibular posterior bone had the densest cortical bone in both sexes, followed by, mandibular anterior, maxillary posterior and maxillary anterior areas in males. Nevertheless, in females, the sequence of bone density locations from highest to lowest was maxillary posterior, maxillary anterior and mandibular anterior areas. Cortical bone is known to increase in thickness from the anterior to the posterior mandible. ${ }^{(11)}$ Moreover, Orenstein et al. ${ }^{(19)}$ reported that the mandible is generally denser than the maxilla, anterior bone is generally denser than posterior bone, and the anterior mandible has the densest bone followed by the posterior mandible, the anterior maxilla, and the posterior maxilla.

Choe et al. ${ }^{(12)}$ found an increase in bone Dity from posterior to anterior areas except for the mandibular buccal side, which had no significant difference. The highest bone density was recorded between the central and lateral incisors. In the mandible, the buccal side between the first and second molars had the highest value. Any variation from this study may be due to the sample which was edentulous subjects receiving dental implant or the methodological tools. In addition, the difference might have been due to the variations in the age and the gender of the patients or might be due to the use of different types of software.

In this study, comparisons of bone density between both sexes have shown significant differences in the some of the measurements. Moreover, it was found that males exhibited a higher bone density than females. These results are in agreement with other investigators which indicated that the lack of sex differences may be attributed relatively to age of participants ${ }^{(11,12)}$. In this study, females exhibited a higher bone density in the posterior maxilla than males. This was in disagreement with Sogo et al. ${ }^{(5)}$ who found that females exhibited a lower bone density in the posterior maxilla than males, and that age-related loss of bone was not pronounced. This variation might be due to the including of the trabecular bone and the outer cortical shell. It is very difficult to make a direct comparison with the previous studies as most of them included cadaver specimens or edentulous patients.

Yong et al. ${ }^{(20)}$ indicated that in female, the changes in bone density according to age showed a cubic form. They indicated that the bone density increased in the third to fifth decades, reached the peak value at approximately 35 years of age, and decreased slowly until 50 years of age, with a rapid decrease thereafter.

According to the results of this study, it is concluded that longer orthodontic screw implants in the mandible may not enhance stability as in the maxilla, but the diameter might affect stability. Moreover, in thick, dense cortical bone, drill-free screws can cause fracture of the screw implants and more bone damage. It has also been suggested that screws should be placed with a pre-drilling method in the buccal mandibular particularly at higher locations.

\section{CONCLUSIONS}

Bone density at different sites was measured in Hounsfield units.

1. In a comparison of the bone density 
according to the height of the location from the alveolar bone crest at each site, bone density tended to increase with increasing height.

2. Mean bone density showed a progressive increase from the posterior to the anterior areas.

3. A comparison of mean bone density between the males and females showed that the males had higher values than females with significant difference in some variable at the posterior areas.

\section{REFERENCES}

1. Baumgaertel S, Hans MG. Buccal cortical bone thickness for mini-implant placement. Am J Orthod Dentofacial Orthop. 2009; 136(2):230-235.

2. Huang LH, Shotwell JL, Wang HL. Dental implants for orthodontic anchorage. Am J Orthod Dentofacial Orthop .2005; 127(6):713-722.

3. Samrit V, Kharbanda OP, Duggal R, Seith A, Malhotra V. Bone density and miniscrew stability in orthodontic patients. Aust Orthod J. 2012; 28(2):204-212.

4. Sntiago RC, de Paula FO, Fraga MR, Picorelli Assis NM, Vitral RW. Correlation between miniscrew stability and bone mineral density in orthodontic patients. Am J Orthod Dentofacial Orthop. 2009; 136(2):243-250.

5. Sogo M, Ikebe K, Yang TC, Wada M, Maeda Y.Assessment of bone density in the posterior maxilla based on Hounsfield units to enhance the initial stability of implants. Clin Implant Dent Relat Res. 2012;14 Suppl 1:e183-187.

6. Nackaerts O, Jacobs R, Horner K, Zhao F, Lindh C, Karayianni K, et al. Bone density measurements in intra-oral radiographs. Clin Oral Invest. 2007; 11(3):225-229.

7. Marquezan M, Lau TC, Mattos CT, Cunha AC, Nojima LI, Sant'Anna EF, et al. Bone mineral density. Angle Orthod. 2012; 82(1):62-66.

8. Turkyilmaz I, Tozum TF, Tumer C. Bone density assessments of oral implant sites using computerized tomography. J Oral Rehabil. 2007; 34(4):267-272.

9. Homolka P, Beer A, Birkfellner W, Nowotny R, Gahleitner A, Tschabitscher $\mathrm{M}$, et al. Bone mineral density measurement with dental quantitative CT prior to dental implant placement in cadaver mandibles: pilot study. Radiology. 2002; 224(1):247-252.
10. Deguchi T, Nasu M, Murakami K, Yabuuchi T, Kamioka H, TakanoYamamoto T. Quantitative evaluation of cortical bone thickness with computed tomographic scanning for orthodontic implants. Am J Orthod Dentofacial Orthop. 2006; 129(6):721 e727-712.

11. Park HS, Lee YJ, Jeong SH, Kwon TG. Density of the alveolar and basal bones of the maxilla and the mandible. Am J Orthod Dentofacial Orthop. 2008; 133(1): 30-37.

12. Choi JH, Park CH, Yi SW, Lim HJ, Hwang HS. Bone density measurement in interdental areas with simulated placement of orthodontic miniscrew implants. Am J Orthod Dentofacial Orthop. 2009; 136(6):766 e 761-712.

13. Han S, Bayome M, Lee J, Lee YJ, Song $\mathrm{HH}$, Kook YA. Evaluation of palatal bone density in adults and adolescents for application of skeletal anchorage devices. Angle Orthod. 2012; 82(4):625-631.

14. Moon SH, Park SH, Lim WH, Chun YS. Palatal bone density in adult subjects: implications for mini-implant placement. Angle Orthod. 2012; 80(1):137-144.

15. Jeong KI, Kim KS, Oh JS, Jeong MA. Consideration of various bone quality evaluation methods. Implant Dent. 2013; 22(1):55-59.

16. Shahlaie M, Gantes B, Schulz E, Riggs M, Crigger M. Bone density assessments of dental implant sites: 1. Quantitative computed tomography. Int J Oral Maxillofac Implants. 2003; 18(2):224-231.

17. Shapurian T, Damoulis PD, Reiser GM, Griffin TJ, Rand WM. Quantitative evaluation of bone density using the Hounsfield index. Int J Oral Maxillofac Implants. 2006; 21(2):290-297.

18. Humphries SM. Comparison of cortical bone thickness between second premolars and first molars in the maxilla and mandible in four ethnic groups [MSc thesis]. California: University of Southern California; 2007. Pp 57-58.

19. Orenstein IH, Synan WJ, Truhlar RS, Morris HF, Ochi S. Bone quality in patients receiving endosseous dental implants: DICRG interim report no.1. Implant Dent. 1994; 3:90-94.

20. Yong SJ, Lim SK, Huh KB, Park BM, Kim NH. Bone mineral density of normal Korean adults. J Korean Med Assoc. 1988; 31:1350-1358. 